\title{
Improvement of fault interpretation with seismic attribute analysis of Jeju Basin, offshore southern Korea, East China Sea
}

\author{
${ }^{1}$ Department of Earth and Environmental Sciences, Chungbuk National University, Cheongju, Republic of Korea; *Corresponding author, \\ E-mail: jhontawoo@gmail.com \\ ${ }^{2}$ Domestic Business Unit, Korea National Oil Corporation, Ulsan, Republic of Korea
}

(Received: January 14, 2021; Revised accepted: May 14, 2021)

https://doi.org/10.18814/epiiugs/2021/021010

Seismic attribute analysis is useful in identifying faults and quickly visualizing their 3-D geometrical features. This study presents seismic attribute analysis of 3-D seismic reflection data acquired from the Jeju Basin, offshore southern Korea for fault interpretation. To improve the accuracy of the fault interpretation, noise reduction and spectral enhancement were conducted prior to the seismic attribute analysis. The pre-conditioned seismic volume was used to generate three seismic attribute volumes: dip, tensor, and structurally oriented semblance. These three attribute volumes were co-rendered to compare three different structural attributes effectively. Frequency decomposition volume was created on the basis of the scale, so geological features can be distinctively resolved. Based on the multi-attribute analysis, we quickly identified structural features and accurately interpreted the fault patterns based on their strike direction. Rift-related major faults were identified, and their geometrical characteristics were easily extracted from the 3-D attribute volume. Subtle changes in the strike direction of some normal faults were observed during the rift basin evolution. This observation suggests that the fault development pattern was possibly affected by the change in the magnitude and direction of the extensional stress during the basin evolution or the interaction of the preexisting structural trend and tectonic movement.

\section{Introduction}

A seismic attribute is a quantitative property that can be directly detected or mathematically computed from seismic data. Seismic attribute analysis is an important tool for interpreters to quickly and precisely reveal geological features such as faults and sedimentary bodies (Taner et al., 1994; Chopra and Marfurt, 2007). Seismic attribute analysis has been used since the 1970s and more than 300 attributes have been defined (Taner, 2001; Chopra and Marfurt, 2005; Brown, 2011). The changes in the seismic attributes are clearly marked along the faults or fractures because of differences in lithology, density, con- tinuity, and waveform. Seismic waveforms or amplitudes can also vary with stratal discontinuities such as sequence boundaries, erosion surfaces, and unconformities.

Fault interpretation of seismic data has been widely used to recognize stratal deformation, understand tectonic movement, and find hydrocarbon-bearing traps (Aki, 1968; Mansfield and Cartwright, 1996; Langhi et al., 2010). 3-D seismic data allow us to effectively visualize the image of faults and easily identify their spatial distribution. Although high-resolution 3-D seismic reflection data have advantages, it is difficult to distinguish faults with a throw of less than $15-20 \mathrm{~m}$ on the seismic section (Fossen, 2016). 3-D seismic interpretation is commonly elaborated with 3-D seismic attribute analysis to improve fault image and interpretation resolution of fault geometry (Bahorich and Farmer, 1995; Cohen et al., 2006; Iacopini and Butler, 2011; Hale, 2013).

Previous studies on the seismic attribute analysis were mainly conducted to visualize and interpret fault systems in seismic data by calculating numerous seismic attributes such as amplitude, frequency, phase, attenuation, and time (Chopra and Marfurt, 2007; Jibrin et al., 2013; Pigott et al., 2013; McArdle et al., 2014). In this study, dip, tensor, and structurally oriented semblance (SO semblance) attribute were generated to investigate the fault development patterns related to the rift evolution of the Jeju Basin, offshore southern Korea (East China Sea).

\section{Geological Setting}

The study area is located in the northeastern part of the East China Sea Shelf Basin, which consists of the Domi, Jeju, and Xihu basins (Fig. 1). The Jeju Basin is divided by the Hupijiao Rise into the Domi Basin to the northeast and the Xihu Depression to the southwest. The basin occupies part of Blocks 4, 5, and 6 on the Korean continental shelf and subzones 1, 2, and 4 in the Korea-Japan Joint Development Zone (JDZ) (Kwon et al., 1995; Yun et al., 1999). The Jeju Basin consists of four mega-sequences (MS 1 MS 4) that represent the tectonically controlled phases of basin development.

MS 1 consists of fluvio-lacustrine sediments, some upper coastal deposits interbedded with volcanoclastic rocks, and thin coal beds (Yun et al., 1999; Kwon and Boggs, 2002). MS 2 is comprised of sandstone and mudstone with interbeds of conglomerate, coal, and freshwater limestone, which were deposited in fluvial to lacustrine 


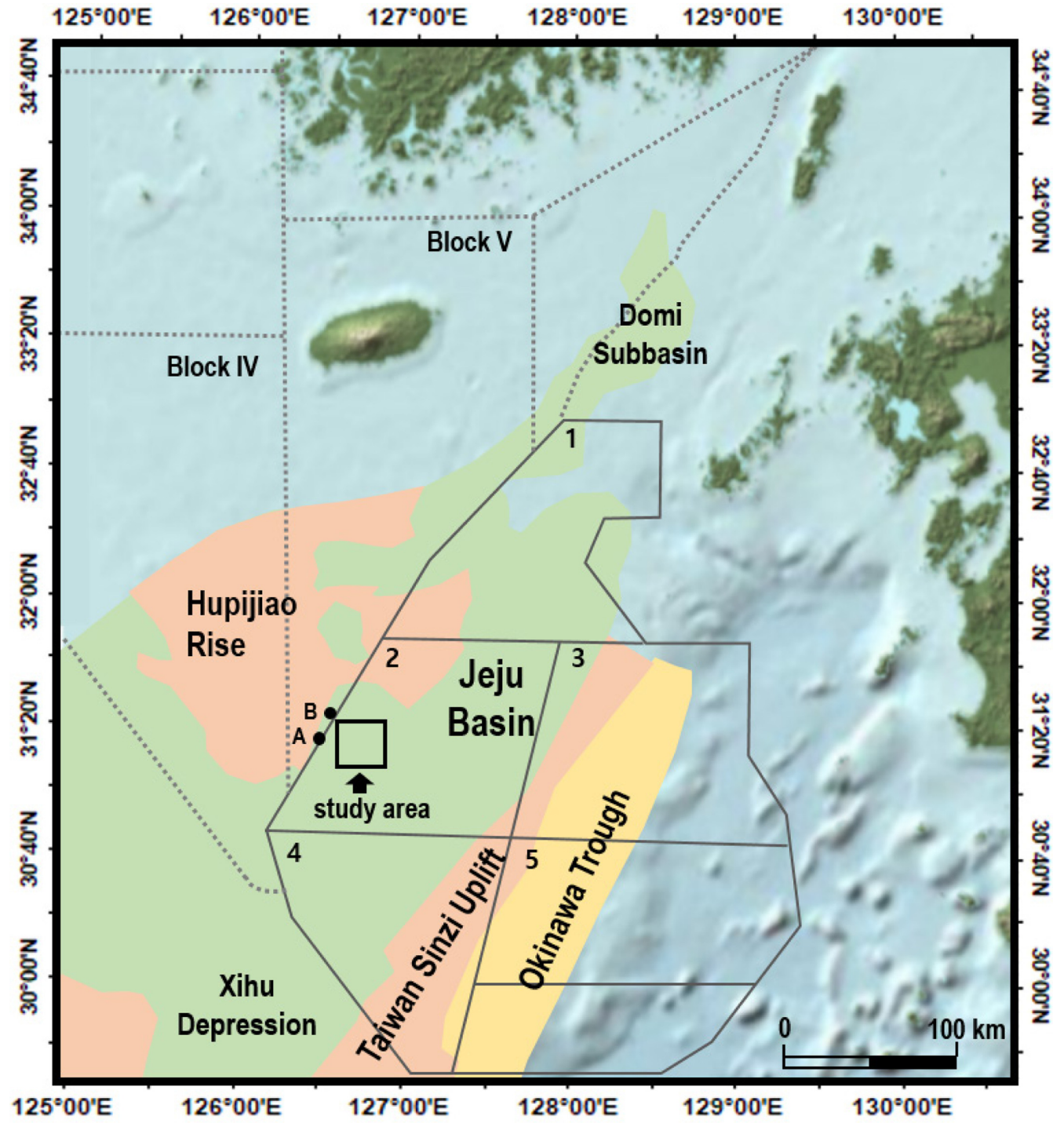

Figure 1. Location of sedimentary basins and structural elements of the East China Sea region. The study area is located in the Subzone 2 of the Korea-Japan Joint Development Zone (JDZ) colored in dark gray lines. A and B indicate the nearest wells.

environments (Kwon and Boggs, 2002). MS 3 mainly consist of sandstone and mudstone with coalbeds deposited in fluvial environment. MS 4 is divided by upper and lower unit, the lower unit consisting of semi- or unconsolidated sandstone and mudstone with thin coal beds (Lee et al., 2006). The upper subunit is generally finer grained and contains shell fragments. In terms of depositional environment, the lower unit and the upper unit are interpreted coastal plain and marine environment, respectively (Yun et al., 1999). The mega-sequence boundaries in seismic sections are correlated with the nearest well A unconformity and their respective geological ages that were derived from biostratigraphy (Yun et al., 1999; Lee et al., 2006) (Fig. 2).

Two phases of rifting have affected the tectonic evolution of the East China Sea Shelf Basin from the Late Cretaceous to Miocene (Lee et al, 2006; Shang et al., 2017; Lee et al., 2018). In the initial rifting phase, graben and/or half-graben structures were formed by the NWSE extension in the Late Cretaceous to Early Eocene (Jilong movement) (Lee et al., 2006; Ye et al., 2007; Cukur et al., 2011). The extensional stress was driven by the subduction of the Pacific Plate beneath the Eurasian Plate (Shang et al., 2017). Subsequent thermal subsid- ence dominantly occurred during the Eocene (Yang, 1992). The western depression of the basin experienced regional uplift during the Late Eocene to Early Oligocene (Yuquan movement) (Cukur et al., 2011; Zhang et al., 2016). During early Oligocene, the basin experienced a second rifting phase, which turned into a post-rifting phase after the Miocene uplift (Zhang et al., 2016; Lee et al., 2018). During the midlate Miocene, when the Pacific Plate subducted to the west, a thrust fold formed at the eastern and southeastern part of the continental shelf of the East China Sea, named the Longjing movement (Zhou et al., 1989; Yang, 1992). At the end of the Longjing movement, regional subsidence and tectonic inversion occurred.

\section{Data and Methods}

3-D seismic reflection data of a full fold area of $561.92 \mathrm{~km}^{2}$ were acquired by the Korea National Oil Company and Japan National Oil Company in the Jeju Basin in 2002. The data has 990 inlines and 2150 crosslines, with spacings of 25 and $12.5 \mathrm{~m}$, respectively. The seismic 

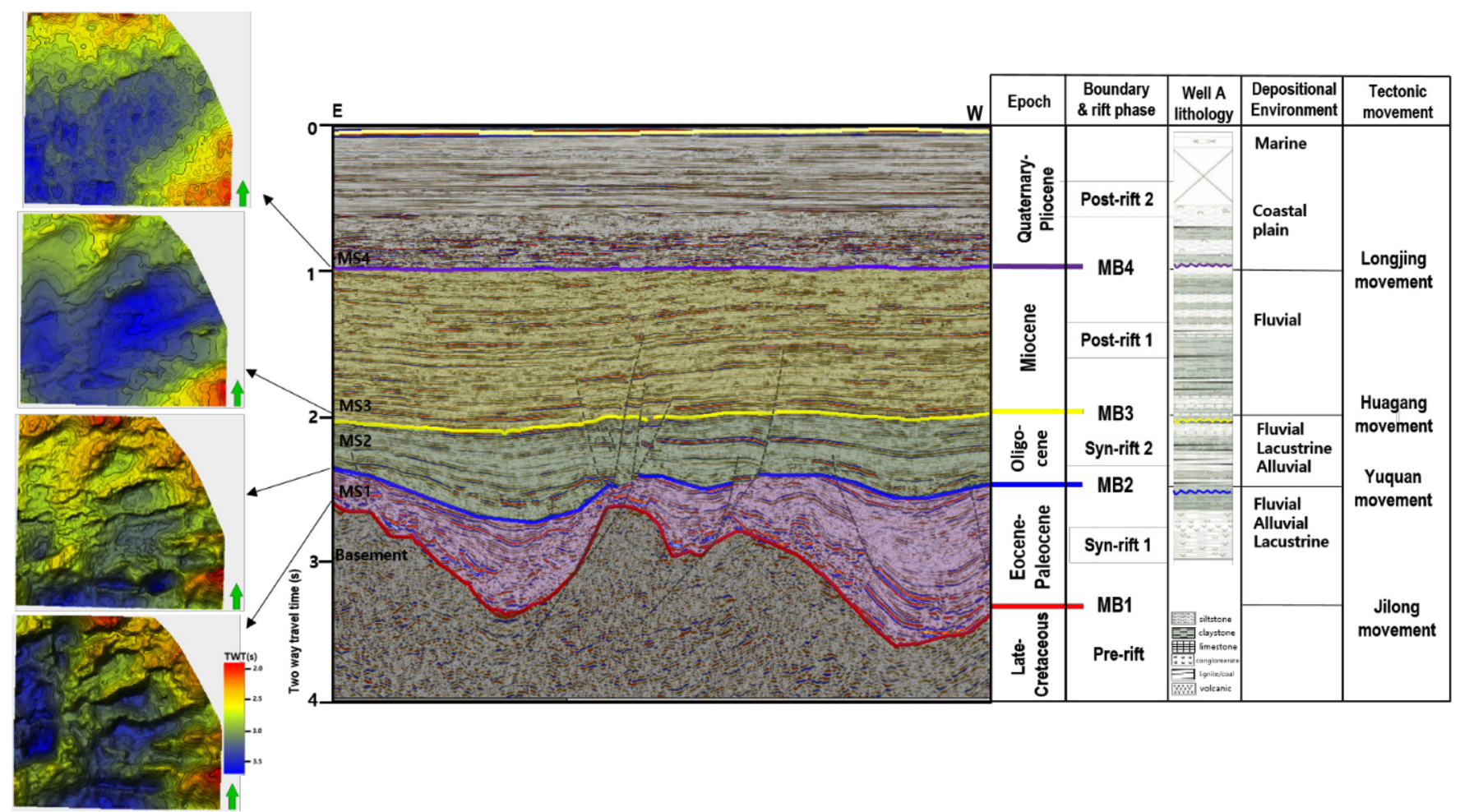

Figure 2. A presentative seismic interpretation and stratigraphic framework of the Jeju Basin. Seismically mapped horizons are denoted as MB1 (mega-sequence boundary 1) MB4. Time structure map for the four mega-sequences (MB1 MB4) are shown on the left. Rift stages, nearest well lithology, and tectonic movements are on the right (modified after Lee et al., 2006; Ye et al., 2007).

recording length was $5120 \mathrm{~ms}$ and the sampling interval was $2 \mathrm{~ms}$. Data processing was carried out in an amplitude-preserved manner, and therefore, the stacked volume reflects structural features well. The stacked section shows fair to good quality through the acquisition and processing (Fig. 2).

To visualize the high-resolution image of the faults, seismic attribute analysis was performed according to the procedure presented in Fig. 3. The workflow comprises a pre-conditioning process and a structural attribute generation process. The preconditioning process removes the seismic noise and enhances the resolution of seismic data using spectral enhancement. The structural attribute generation processes create diverse attributes. Tensor, SO semblance, and dip attributes that are calculated with algorithms that look at different seismic characters such as amplitude, phase, and dip. In this study, three seismic attributes were calculated using user-defined parameters, including amplitude, phase, and dip. These volumes were co-rendered using the GeoTeric 2019 software of ffA. Co-rendering is an approach to visualize the interplay of three separate and contrasting volumes based on RGB (red-green-blue) or CMY (cyan-magenta-yellow) color models. Co-visualization of RGB or CMY colors has proven to be successful with certain classes for 3D seismic attributes (Henderson et al., 2008). Different attributes highlight distinctive features therefore, different colors in one rendered volume will show us all the features with less missing characteristics. The CMY-blended volume was used in this study as it provides a better representation of the structure in the study area. It also represents areas with equal contributions from all three inputs. The blended volume gives us higher confidence in the positioning of faults.

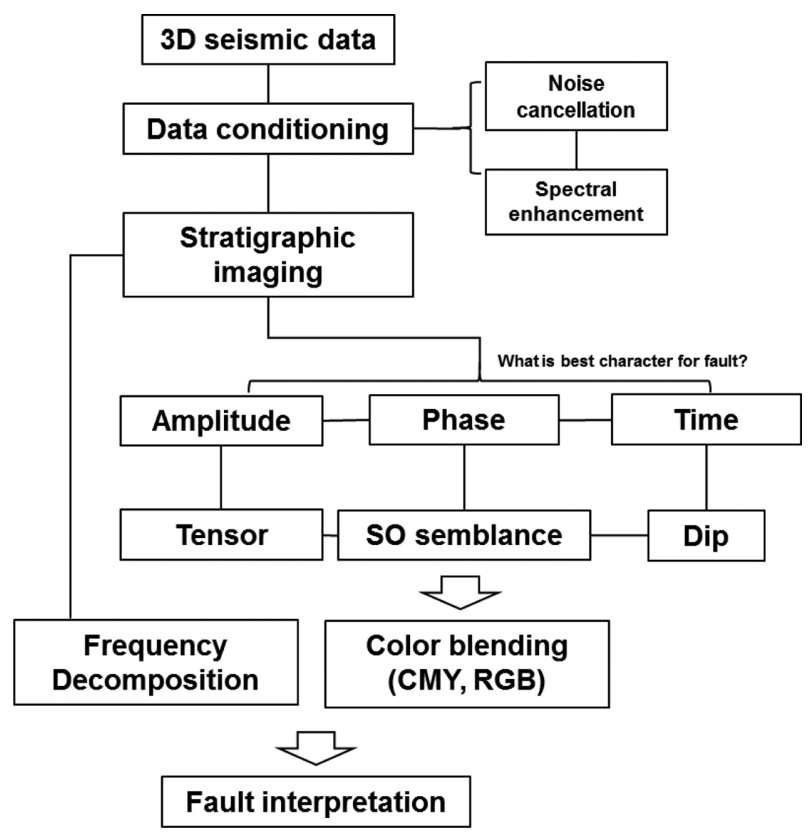

Figure 3. Workflow for seismic-attribute analysis.

From the pre-conditioned seismic data, frequency decomposition volumes were created using the range of 19,24 , and $35 \mathrm{~Hz}$ frequency. Constant $\mathrm{Q}$ frequency decomposition analysis was performed on the basis of the scale, so geological features are to be separated.

Based on the improved attribute volume, we extracted the fault plane and its strike direction to interpret the change in the extensional 
stress during the basin evolution. We also estimate the fault displacement and throw components. Displacement-distance (T-x) plots are constructed to show the displacement and throw differences at the mega-sequence boundaries.

\section{Seismic attribute Analysis}

\section{Enhancement of 3-D Seismic Data Resolution}

There are various methods to enhance poststack seismic data resolution: increase signal-to-noise ratio( $\mathrm{S} / \mathrm{N})$, emphasize strata discontinuity using spectral balancing, and increase dominant frequency (Chopra et al., 2011). In this study, we applied two steps to remove noise. Structurally oriented finite impulse median hybrid (SOFMH) filter was designed to remove noise and to maintain structural shape (Henning and Paton, 2011). The SOFMH filter is a structurally oriented edge-preserving filter. It focuses on reducing the overprint of structured coherent noise while preserving subtle details such as edges, corners, and sharp dips in the structure. Next, a random noise filter was applied to remove residual noise.

Spectral enhancement, bandpass filters, and high and low-pass filters can be used to improve the quality of the seismic data. In this study, a spectral enhancement technique was selected to enhance the resolution of seismic data. The analysis window is centered at $2268 \mathrm{~ms}$, which is located between MB1 (top of Eocene) and MB2 (top of Oligocene). Dominant frequency and bandwidth were maintained at $37.1 \mathrm{~Hz}$ and $33.2 \mathrm{~Hz}$, respectively. The mean frequency is adjusted from $29.55 \mathrm{~Hz}$ for the input data to $35.27 \mathrm{~Hz}$ for the output data. These pre-conditioned processes were useful for improving the vertical resolution of the seismic data prior to the attribute analysis (Fig. 4).

\section{Attribute Analysis}

Previous work published about the seismic attribute analysis to the 2-D seismic section used to emphasis on the seismic facies interpretation (Pigott et al., 2013). 3-D seismic attributes have robust advantages in visualizing their topography and defining the structural interpretation. The seismic attribute can be divided into geometrical attributes based on reflection configurations and physical attributes based on reflection characteristics (Taner et al., 1994). Geometrical attributes are suitable for stratigraphic and structural analyses. The major geo-

(a)

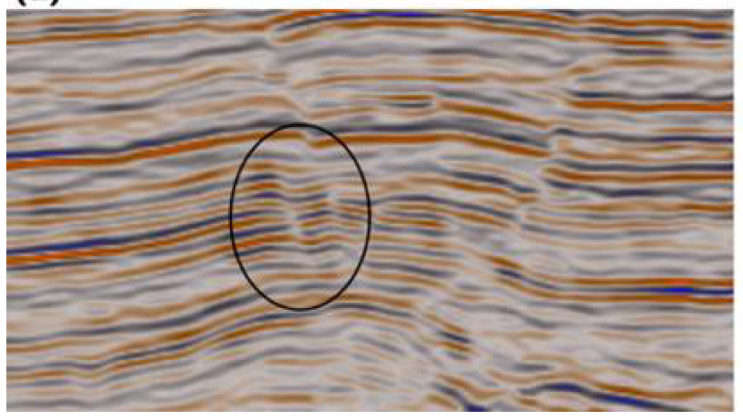

Figure 4. A selected seismic section at crossline 2025 after performing (a) noise reduction and (b) spectral enhancement. Note the improved quality within the ellipse in (b). metric attributes are dip, azimuth, coherence, and curvature. Physical attributes are related to physical components measured or computed from time, amplitude, phase, and frequency of seismic reflection data. To visualize the fault system we utilized the dip, tensor, and SO semblance attributes.

The dip attribute is one of the geometric attributes. Dip and azimuth are used to define the orientation of the strata in 3-D space. These are calculated at each point within the seismic data volume. Down the steepest part of the local structure as indicated by the maximum dip direction.

$$
\operatorname{Dip}=\sqrt{\left(\left(\frac{d t}{d x}\right)^{2}+\left(\frac{d t}{d y}\right)^{2}\right)}
$$

The first $\frac{d t}{d x}$ is the difference in the $\mathrm{x}$-axis direction, and the second $\frac{d t}{d y}$ is the difference in the y-axis direction, and the unit of dip is $\mathrm{ms} \mathrm{m}^{-1}$ (Dalley et al., 2007).

The tensor attribute emphasizes edges that are detected by amplitude change and highlights amplitude terminations (McArdle et al., 2014). A high value of the tensor indicates a high likelihood of a fault plane. This attribute is based on a local structural tensor, which is analyzed to find the dominant direction of the reflectors and their structure. This is an appropriate attribute for analyzing structures related to the principal directions of seismic reflection (Harris and Stephens, 1988). The tensor attribute can show clear results on time slices, although it can be a little blurry in the vertical section. The use of the tensor attribute helps to define the lateral continuity of faults.

The change in the tensor attribute refers to the amount of differences between the two position vectors. The eigenvalue decomposition of the tensor attribute is the presentation of two results in $\left(\lambda_{1}, \lambda_{2}\right.$, $\left.\lambda_{3}\right)$ eigenvalues and $\left(\boldsymbol{e}_{1}, \boldsymbol{e}_{2}, \boldsymbol{e}_{3}\right)$ eigenvectors. The interpretation of these components can be visualized as a 3-D ellipse whose radius is the same as the eigenvalues in descending order and directed along their eigenvectors. In the case of 3-D data, the structural tensor(S) is expressed as follows:

$$
S=\left[\begin{array}{ccc}
I_{x}^{2} & I_{x} I_{y} & I_{x} I_{z} \\
I_{x} I_{y} & I_{y}^{2} & I_{y} I_{z} \\
I_{x} I_{z} & I_{y} I_{z} & I_{z}^{2}
\end{array}\right]
$$

Here, $I$ is the gradient and $x, y, z$ representing inline, crossline, time directions respectively.

\section{(b)}

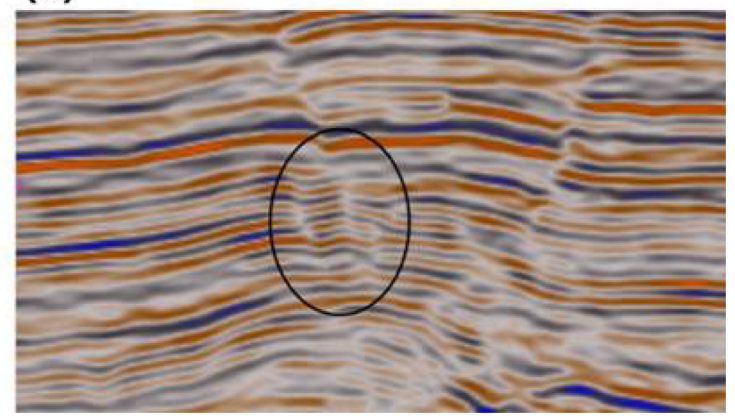



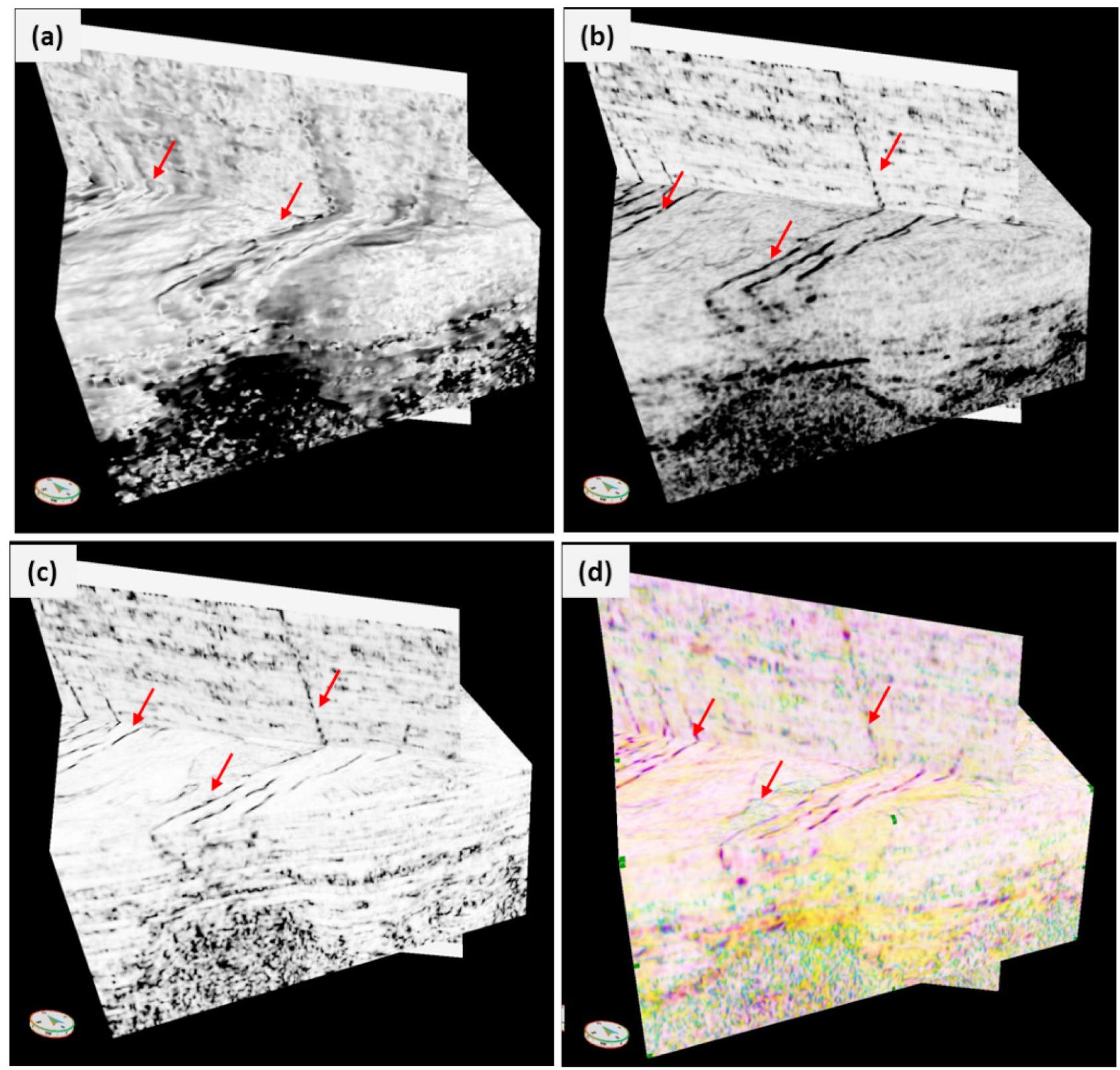

Figure 5. Results of the seismic attribute analysis for 3-D seismic data from the Jeju Basin. Fault planes are well imaged in (a) dip, (b) tensor, (c) SO (structurally oriented) semblance, and (d) co-rendered volumes. Red arrows indicate faults.

SO semblance computes the eigenstructure by forming a covariance matrix from the traces of the analytical data (Gersztenkorn and Marfurt, 1999). The semblance attributes are sensitive to edges that are picked up as phase and amplitude changes (McArdle et al., 2014). This is an appropriate attribute for identifying diverse types of faults (large- or small-scale fault) and the fastest method among the three algorithms (Marfurt et al., 1998). It is also suitable for identifying the antithetic faults formed by the main fault system. The results of each attribute analysis are shown in Fig. 5.

\section{Fault Enhancement/detect Filter}

Frequency decomposition was applied to enhanced seismic volume (Fig. 6a). The Constant Q frequency decomposition employs bandpass filters to carry out decomposition processing strategy sim- ilar to a Continuous Wavelet Transform (CWT). The main benefit from this technique is the increased vertical resolution due to flexible filter length and bandwidth, reducing the filter length at higher frequencies. Therefore, it is efficient to optimize the processing parameters.

Fault enhancement and detect filter was applied to improve the fault continuity. The fault-enhance filter uses a Gaussian smoothing filter which improve the continuity of faults reducing the background noise from the seismic attribute volume. This enhancement is the prerequisite processing step to identity and extract small-scale and largescale faults. By adjusting the fault strike NE-SW and E-W direction, we could more clearly extract potential faults which are continuously mapped north-eastward (Fig. 6b). Those fault planes can be provided with time change according to the rifting stages. 


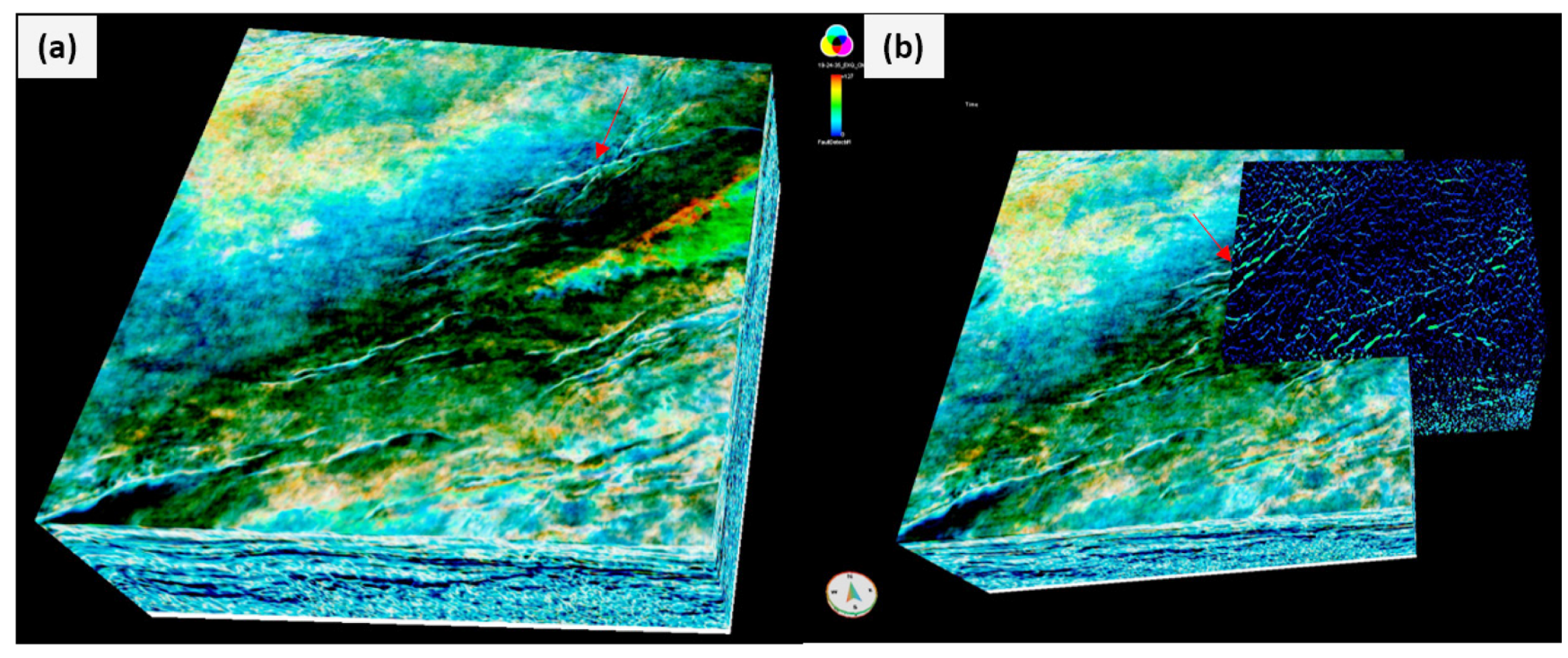

Figure 6. (a) The fault features delineated with frequency decomposition (b) are improved further and continuously mapped north-eastward in the fault extracted volume. Red arrows indicate fault plane.

\section{Visualization of Geological Structures}

A color blend (RGB, HSV, or CMY) is the best way to co-visualize multiple attributes. This tool is effective as it provides a representation of geological information such as faults, channels, lithology, and basement with high-resolution data (Guo et al., 2008; Froner et al., 2013). In CMY blending, the attributes are assigned to each color: cyan for tensor, magenta for SO semblance, and yellow for dip magnitude (Fig. 5). CMY blending is appropriate for recognizing a fault as it will express a high dip magnitude as yellow. Areas where the three independent attribute volumes delineate the same fault are shown in black. Therefore, the areas in black represent a fault with very high confidence. The attribute values of each input volume are normalized, and the change in color indicates a change in the general value (Froner et al., 2013). As a result, the color blending volume is effective in detecting the fault and basement boundaries.

The iso-proportional slicing tool was applied to better visualize fault geometry. We used the iso-proportional slice map generated at each mega-sequence boundary to identify the fault pattern, the fault plane direction, and visualize their depositional environment (Fig. 7).

\section{Structural Analysis}

\section{Seismic Stratigraphy and Fault Development Pattern}

Based on the seismic reflection termination and configuration, the top of the acoustic basement and three regional unconformities are identified: MB1 (mega-sequence boundary 1), MB2, MB3, and MB4 in ascending order (Fig. 2). Horizon interpretation is an important step to make the iso-proportional slicing map that are accurately represent to geometrical feature at each mega sequence boundary.

NE-SW striking normal faults are identified from seismic attribute volumes with iso-proportional slicing maps (Fig. 7). These faults are basement-involved normal faults and mostly terminated or linkaged at MB3 (Fig. 7b). Some secondary faults newly formed south area, however only a few fault remnant at MB 4 (Fig. 7a). The Jeju Basin experienced two phases of the rift stage during the Paleocene to Oligocene period (Lee et al., 2006; Shang et al., 2017). The main rift stage occurred from Paleocene to Eocene, forming graben and half-graben structures. The seismic units bounded by the mega-sequence boundaries reflect depositional sequences that formed during tectonically controlled basin development (Lee et al., 2006; Cukur et al., 2011; Lee et al., 2018).

MB1 is recognized as the deepest and mappable reflector observed in the 3D seismic data (Fig. 2), which represents the top of the acoustic basement. The top of the acoustic basement is characterized by high amplitude and good lateral continuity. The acoustic basement exhibits chaotic reflections or reflection-free features. According to biostratigraphic studies, the acoustic basement formed prior to the Eocene (Yun et al., 1999) and consists mainly of alluvial to fluvio-lacustrine deposits (Kwon and Boggs, 2002; Lee et al., 2006; Cukur et al., 2011). Four-dimensional structural model indicates the depo-center created between the basement-involved normal faults (Fig. 8). The seismic cross section shows that the rift-related faults dip to the north in the southern part of the study area, while to the south in the northern part (Fig. 8). Such an inward-dipping normal fault system typically formed a series of grabens and half-grabens. The orientation of the fault system indicates that the rift-related extension was dominated by NW-SE or $\mathrm{N}-\mathrm{S}$ directions (Fig. 8).

MB2 is an angular unconformity marked by reflector termination patterns (Fig. 2). The underlying depositional sequence is confined to half-graben or graben structures separated by basement highs. This sequence is typical to half- graben or graben fills controlled by normal faulting and related fault block rotation. The timing of the fault activity was reported to be approximately Eocene (Yun et al., 1999). The fault-controlled depressions were filled by fluvial to lacustrine successions (Kwon and Boggs, 2002; Lee et al., 2006; Cukur et al., 2011). The first phase of the rift stage was interrupted by the Yuquan movement, which caused a change in the tectonic regime from exten- 

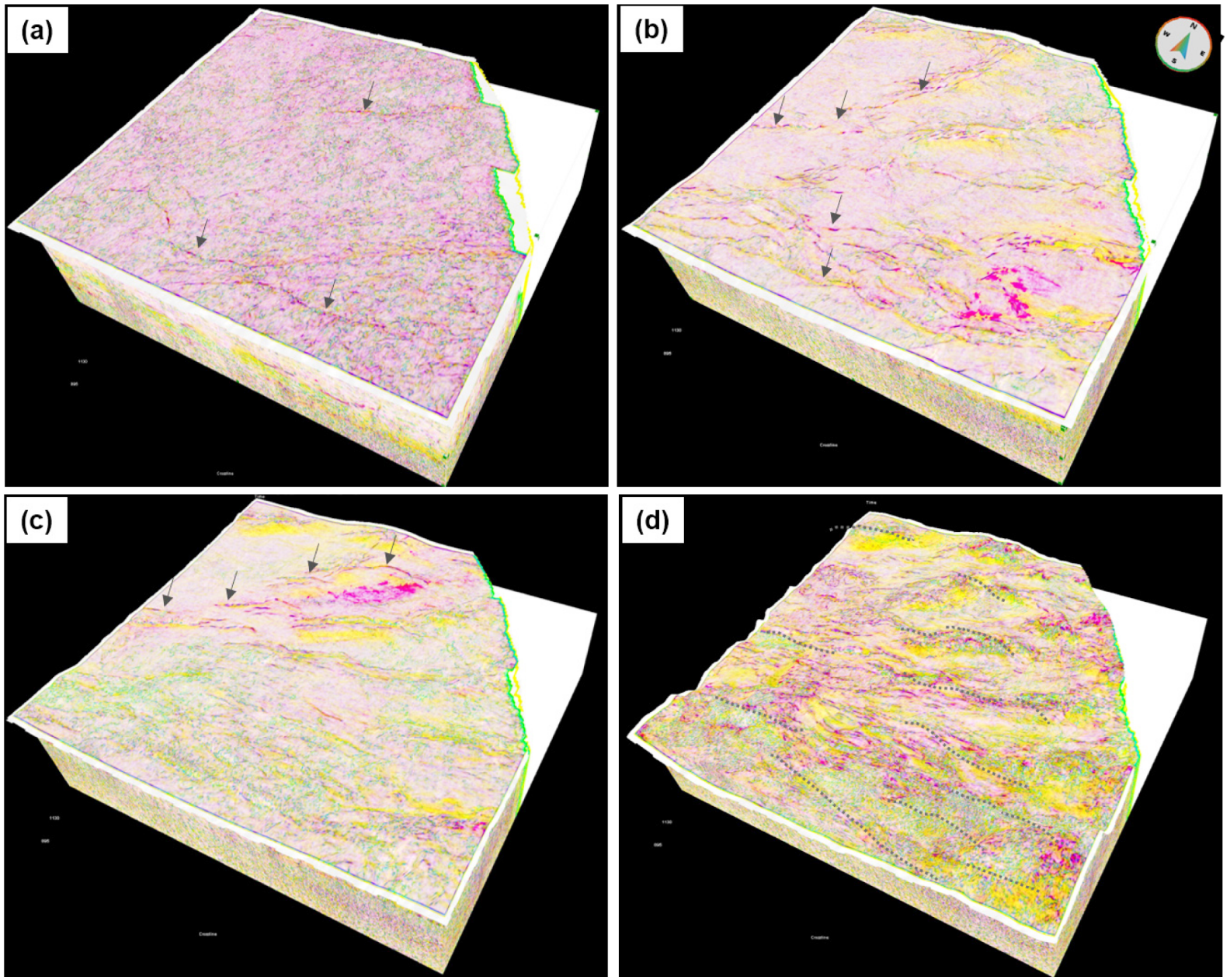

Figure 7. Iso-proportional slice maps with CMY color blending attributes generated at each mega-sequence boundary including (a) top of Miocene (MB4), (b) top of Oligocene (MB3), (c) top of Eocene (MB2), and (d) top of acoustic basement (MB1). Black arrows and gray dot line indicate faults.

sion to compression (Zhou et al., 1989; Cukur et al., 2011; Shang et al., 2017).

MB3 is characterized by variable amplitude reflectors with moderate continuity (Fig. 2). It is an angular unconformity, or a conformable surface correlated with the unconformity. The underlying depositional sequence is less faulted and deformed than half-graben or graben fills. The depositional age of the sequence was reported to be approximately Oligocene (Yun et al., 1999). MB3 was interpreted as the top of the Oligocene. The subdued fault activity suggests that the extensional force involved waned during the Oligocene. The Oligocene depositional sequence was formed in fluvial to marginal sea environments (Kwon and Boggs, 2002; Lee et al., 2006; Cukur et al., 2011). During the second phase of the rift stage, the Oligocene syn-rift fill was accommodated by the progressive deepening and expansion of the initial grabens and half-grabens (Fig. 8b). The iso-proportional map of the top Oligocene horizon shows that the rift-related faults are involved in the pre-rift basement (Fig. 7). Some secondary faults newly formed in response to fault reactivation. The rift stage ceased with the regional uplifting movement (Huagang movement) during the early Miocene and transitioned to the post-rift phase (Zhou et al., 1989; Shang et al., 2017).

MB4 is an angular unconformity recognized as high to low-ampli- tude reflector with good continuity. It is relatively flat and conformable with overlying parallel or sub-parallel reflectors. The underlying depositional sequence appears to be deformed by compressional folding, fault-related folding, and basement-involved normal faulting. These deformational structures resulted from the regional compression of the Miocene (Lee et al., 2006; Cukur et al., 2011). Miocene compression is correlated with the Longjing movement caused by regional tectonics (Yang et al., 2004). MB4, which leveled the deformational structures, was assigned to be the top of the Miocene. The Miocene depositional sequence was dominated by fluvial and marine environments. The post-rift stage is separated by angular unconformity (MB4) into the deformed Miocene and the undeformed post-Miocene unit. The angular unconformity formed as a result of the Longing movement. Some of the preexisting rift-related faults were reactivated to extend into the first post-rift unit; however, there are a few mappable faults (Fig. 7a).

\section{Influence of Tectonic Movement}

Paleocene-Eocene rifting created a series of fault block. The eastern part of the study area comprised of series of graben and half graben structure, whereas western part comprised of big graben ( 18 km) (Fig. 8). 

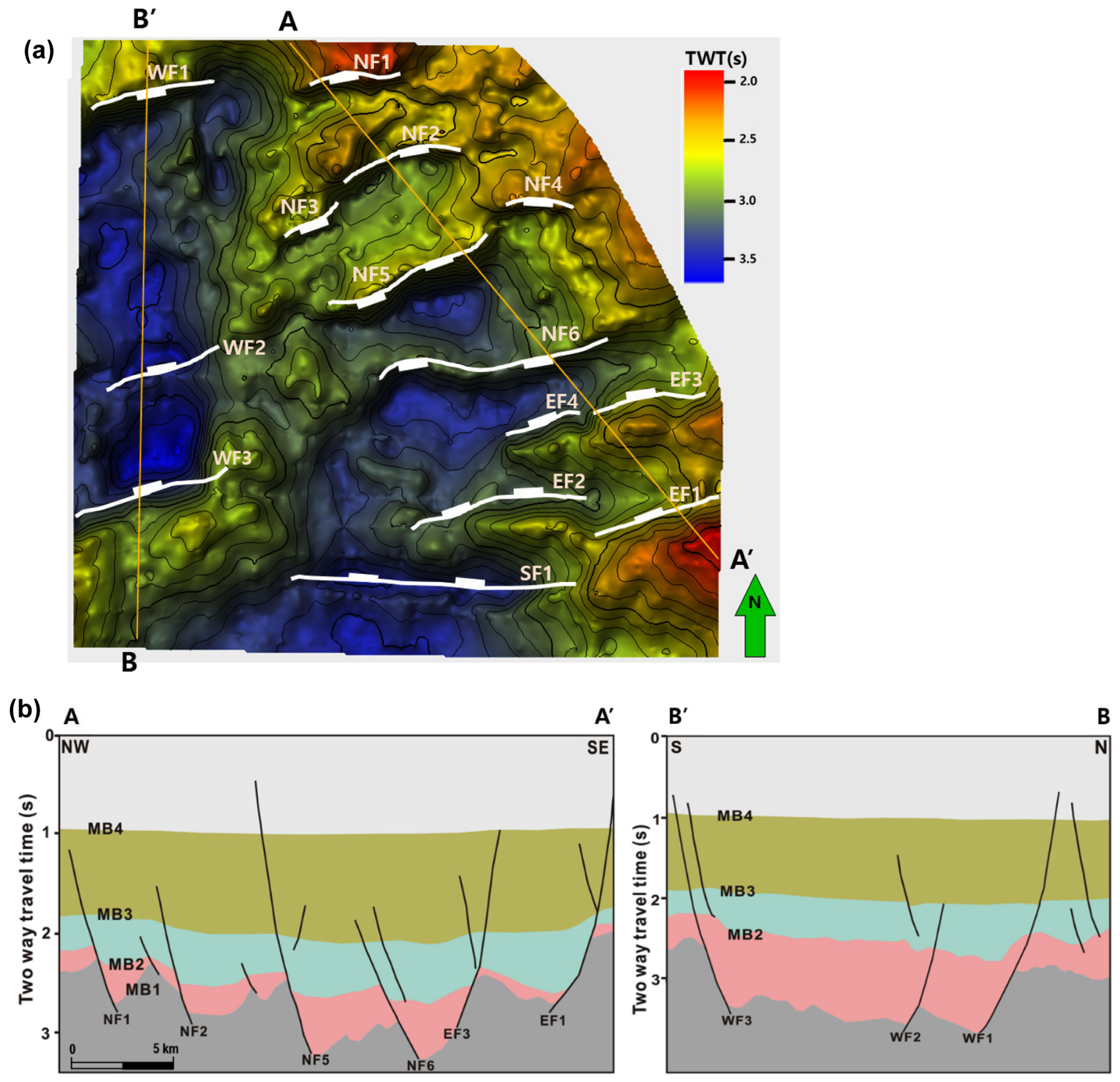

Figure 8. (a) Time structure map (1.91 $3.7 \mathrm{~ms})$ of acoustic basement showing the rift-related normal faults and depressions. (b) Interpretation of the $A A^{\prime}$ and $B B^{\prime}$ seismic sections. A series of normal faults were developed during the rift basin evolution, forming several half-grabens in the eastern part (AA') and a graben formed in the western part (BB') of the study area.

Fault strike and displacement are related to extension direction and strength respectively. In order to examine the extension direction during the basin evolution, we examined the strike direction of a normal fault along the mega-sequence boundaries. The strike direction was extracted from the fault plane for the NF5 fault for the eastern part and the WF3 fault for the western part of the study area. Extracted strike-direction data were plotted on a rose diagram of each mega-sequence boundary (Fig. 9). The strike direction of the NF5 fault ranges from $\mathrm{N} 34^{\circ} \mathrm{E}$ to $\mathrm{N} 87^{\circ} \mathrm{E}$, commonly dominated by the NE-SW direction on MB1. The strike direction shows a shift to the ENE-WSW direction between $\mathrm{MB} 2$ and MB4. The WF3 fault has a strike direction from $\mathrm{N} 45^{\circ} \mathrm{E}$ to $\mathrm{N} 86^{\circ} \mathrm{E}$. The dominant strike direction is the ENE-WSW, but it shifts slightly to the NE-SW from MB1 to MB4.
In the pre-rifting stage, the basement-involved normal faults were initiated. NW-SE extension during Late Cretaceous to Early Eocene created graben and/or half-graben structures and NE-SW direction of the faults under tensional stresses (Lee et al., 2006; Cukur et al., 2011; Shang et al., 2017). The East China Sea Basin was reported to be formed as complex area of pull-apart rift basins, which have large scale normal faulting and strike-slip faulting (Cukur et al., 2011).

During the second phase of rifting, relatively weak extension affects the fault activity. Yuquan movement were accompanied by tectonic inversion (Shang et al., 2017), and the fault direction slightly changed to the northern direction (Fig. 7b). Several studies reported compression-inversion activity was dominated during the Oligocene period (Li et al., 2015, Liang and Wang, 2019). After this syn-rift phase fol- 

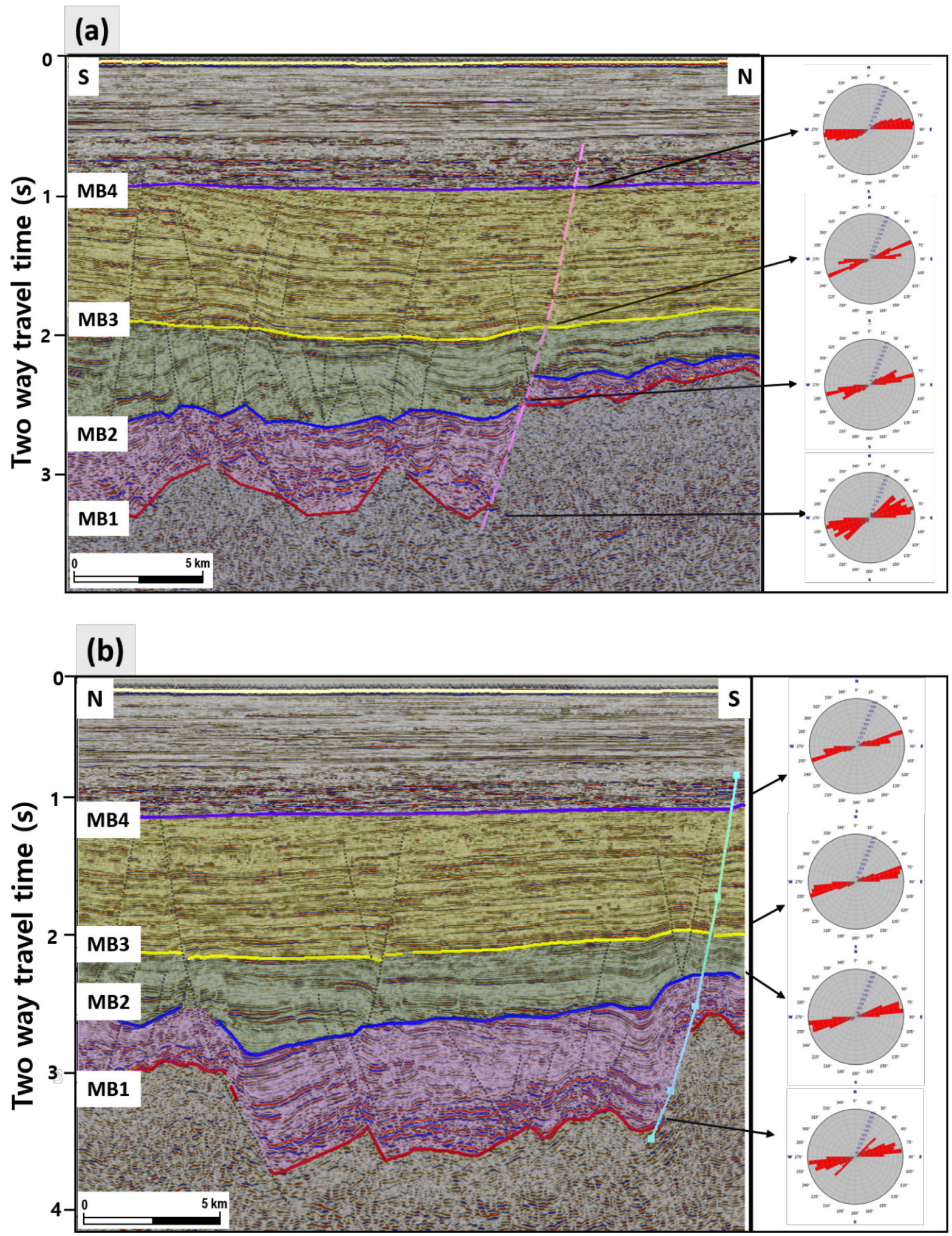

Figure 9. Fault interpretation and rose diagrams showing the change of strike direction at each mega-sequence boundary for (a) NF5 and (b) WF3. For the location of the section, see Fig. 8 .

lowed the Huagang uplift during the Early Miocene.

The fault orientation in the study area is consistent with the regional structural trend caused by the NW-SE direction extension (Yang, 1992; Lee et al., 2006; Cukur et al., 2011). Improved fault interpretation with seismic attribute analysis provided where the fault plane rotated.
Based on the attribute time-slice attributes, the fault plane can be interpreted to have shifted to north direction from Lower Oligocene (time-slice at $2100 \mathrm{~ms}$ ) to Upper Oligocene (time-slice at $1936 \mathrm{~ms}$ ) (Fig. 10). Such a counter-clockwise block rotation are probably caused by the compression-inversion activity during the Huagang Movement. 

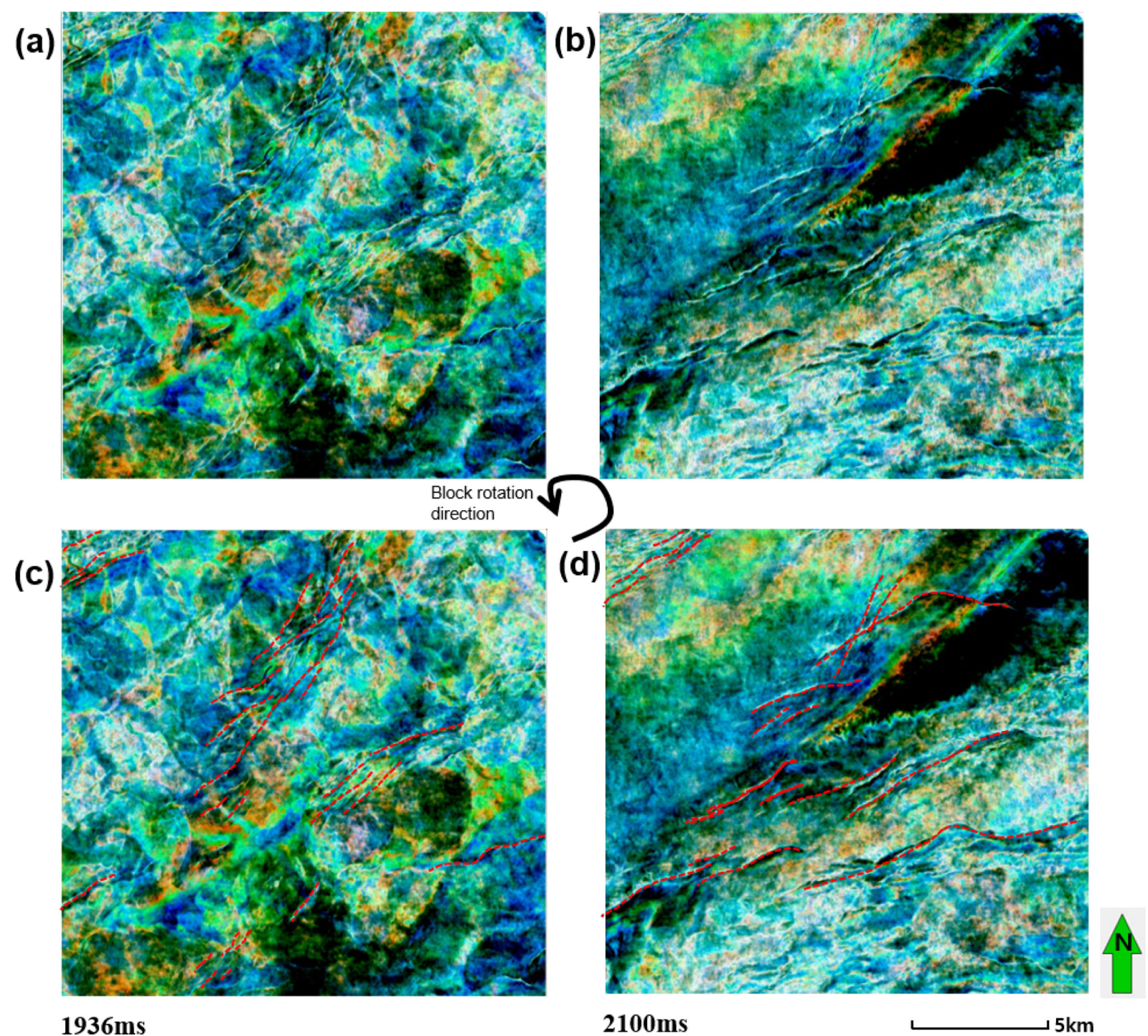

$1936 \mathrm{~ms}$

$2100 \mathrm{~ms}$

Figure 10. Original seismic attribute volume (a) $1936 \mathrm{~ms}$ and (b) $2100 \mathrm{~ms}$. Red dotted lines in (c) and (d) indicate the fault plane in (a) and (b), respectively. Fault plane is interpreted to have rotated to the counter-clockwise direction (from 2100 ms to1936 ms).

The difference in the fault plane orientations is most likely explained by the multiple rifting phases, which possibly lead to slight changes in the extension direction (Bellahsen and Daniel, 2005; Henza et al., 2011). It is also plausible that the preexisting structural trend can affect the fault development pattern during the rift phase. Differential uplift and erosional processes also might have affected sediment transportation and depositional systems, which possibly caused the change in the fault pattern.

\section{Characteristics of Fault Displacement}

The structural model of 3-D seismic data represent four phase of rifting between Paleocene and Pliocene in Jeju Basin (Fig. 11). Detailed structural analysis with 3-D seismic data enabled us to estimate the difference of fault throw and displacement at the mega-sequence boundaries. Different interval velocity was used to calculate the displacement and throw at each mega sequence boundary (Table 1).

The vertical throw profiles were calculated for the intersections at each mege-sequence surfaces. Structural evolution model and fault throw show, that the fault throw significantly decreases upwards (Fig. 11). Extensional energy was maximum during the Paleocene to Eocene for syn-rift phase at MB1 (Fig. 11d). During this stage, basement-involved normal faults were developed and the extensional deformation. Yuquan and Huagang movement affected to deposited mega-sequence 2. After the Huagang movement, the study area entered the post rift stages. The fault throw range significantly decreased.

The fault displacement-distance plots show that fault NF5 is linked with at least five fault segments (Peacock and Sanderson, 1991; Reeve et al., 2015) (Fig. 12). Sudden changes of the displacement value at the stratigraphic boundaries are consistent with the fault growth and linkage characteristics (Dawers and Anders, 1995; Wang et al., 2018). NF5 initially formed from several short fault segments that were linked through several rifting stages. These results indicate the several isolated fault segments at a very early stage in their pre-rifting period and the fault linkaged upward and growing. 

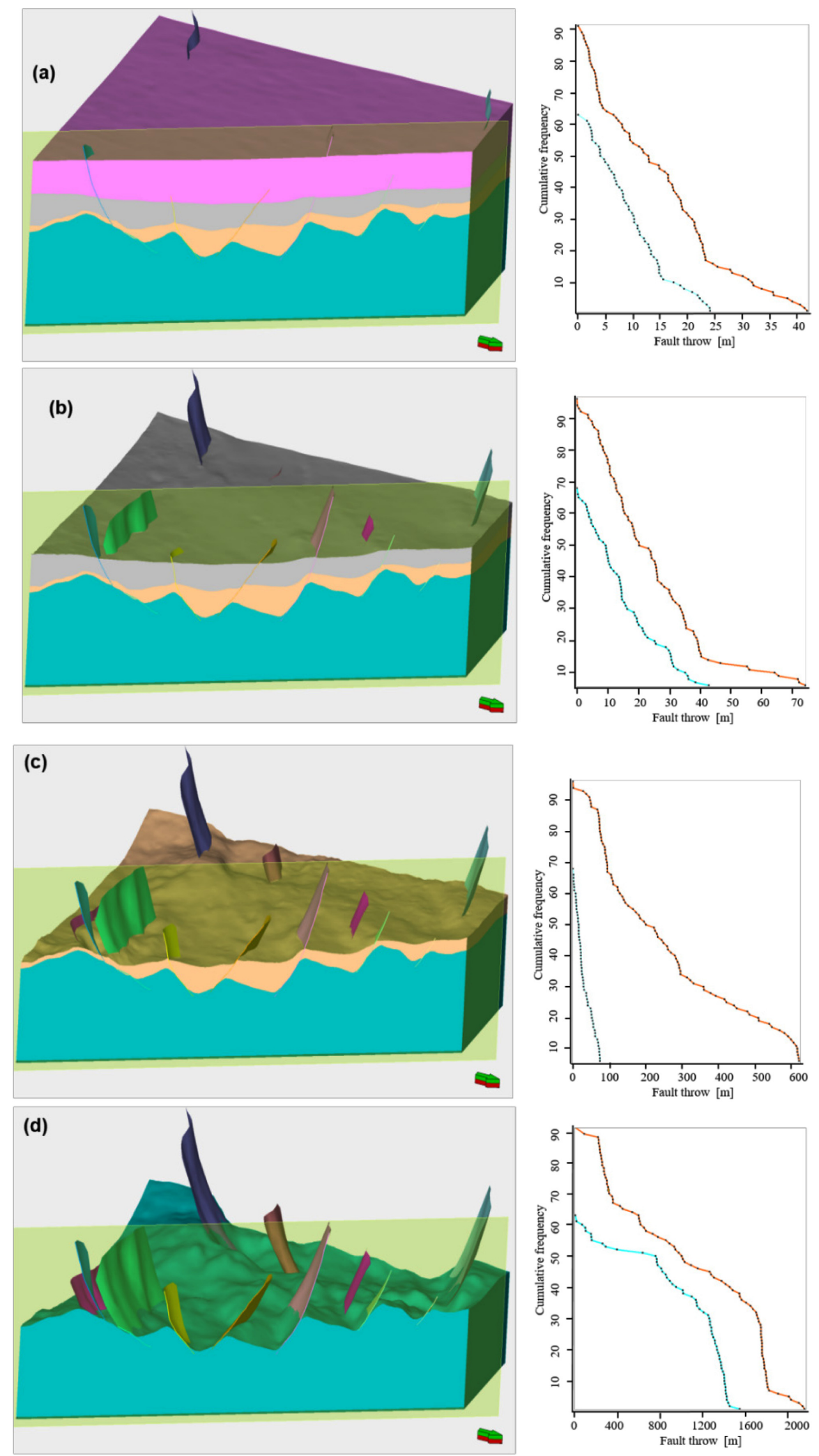

Figure 11. Structural evolution model and fault development pattern of each mega-sequence and the fault throw profile (a) Top Miocene at MB 4, (b) Top Oligocene at MB 3, (c) Top Eocene at MB 2 and (d) Paleocene to Eocene extension and development of series of graben and half graben with $N E$ striking fault and throw profile at $M B 1$. 
Table 1. Calculated fault throw range for each Mega-sequence boundary

\begin{tabular}{|c|c|c|c|c|c|c|c|}
\hline & WF1 & WF2 & WF3 & NF1 & NF2 & NF3 & NF4 \\
\hline MB1 $(4000 \mathrm{~m} / \mathrm{s})$ & 604.38 & 287.99 & 1087.2 & 655.26 & 932.26 & 492.54 & 729.13 \\
\hline $\operatorname{MB} 2(3500 \mathrm{~m} / \mathrm{s})$ & 62.68 & 39 & 54.33 & 62.79 & 69.11 & 86.45 & 28.79 \\
\hline $\operatorname{MB} 3(3000 \mathrm{~m} / \mathrm{s})$ & 4.87 & 4.87 & 9.67 & 12.17 & 10.43 & 11.28 & 17.95 \\
\hline \multirow[t]{2}{*}{ MB4 $(2500 \mathrm{~m} / \mathrm{s})$} & 3.77 & 3.77 & 4.07 & 3.21 & 6.35 & 2.83 & 16 \\
\hline & NF5 & NF6 & SF1 & EF1 & EF2 & EF3 & EF4 \\
\hline MB1 $(4000 \mathrm{~m} / \mathrm{s})$ & 302.46 & 461.57 & 739.96 & 872.29 & 145.28 & 185.45 & 158.94 \\
\hline MB2 $(3500 \mathrm{~m} / \mathrm{s})$ & 95.62 & 99.27 & 81.41 & 355.61 & 218.65 & 81.73 & 93.34 \\
\hline MB3 $(3000 \mathrm{~m} / \mathrm{s})$ & 10.67 & 19.99 & 33.69 & 23.68 & 18.02 & 18.54 & 9.42 \\
\hline MB4 $(2500 \mathrm{~m} / \mathrm{s})$ & 8.35 & 3.37 & 64.14 & 8.27 & 3.74 & 6.28 & 5.2 \\
\hline
\end{tabular}

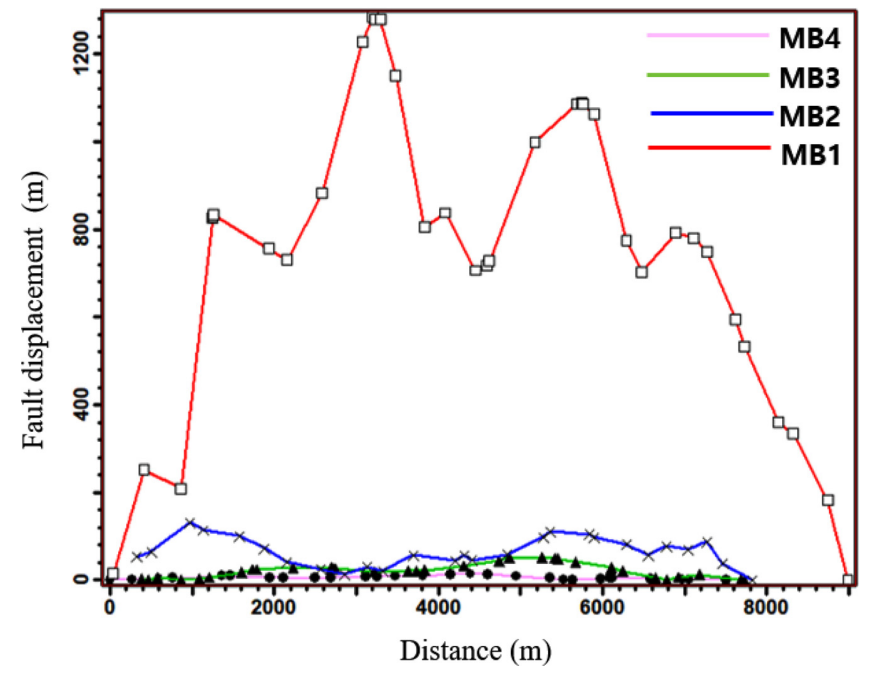

Figure 12. The fault displacement patterns derived from NF5 interpretation are calculated by measuring fault displacement at each surface.

\section{Conclusions}

In this study, 3-D seismic attribute analysis was applied to fault visualization and interpretation of fault development patterns using 3D seismic reflection data collected from the Jeju Basin, offshore Korea. We concluded that dip, tensor, and SO semblance were appropriate seismic attributes for the visualization of faults. CMY color blending and frequency decomposition techniques improved the understanding of the relationship between faults and basement deformation. Based on the improved attribute volumes, the fault development pattern associated with the rift basin evolution was investigated for the Jeju Basin. The main results and conclusions were:

1. The series of NE-SW trending grabens and half-grabens formed as a result of the regional extension direction of NW-SE. The NW$\mathrm{SE}$ regional extension played an important role in the formation of the Jeju Basin.

2. The pre-existing basement normal faults are linkages experienced the several rifting stages. Fault displacement pattern shows a sudden change of the displacement value.

3 . The block rotation occurred by the regional uplifting movement (Huagang movement), which are terminated the synrift stages. The subtle change in the extension direction represents between the western and eastern parts of the study area. Also, the time-slices attribute map show the fault plane have slightly shifted toward the northern direction during uplifting movement.

\section{Acknowledgements}

The authors would like to thank Dr. Gomez (GeoTeric), Prof. Shinn (KMOU) and anonymous reviewers for their constructive comments of the manuscript and thank them for their support with a university software license to GeoTeric 2019, Petrel, and HRS 10. This work was supported by the Basic Research Program (GP2020-006) of the Korea Institute of Geoscience and Mineral Resources (KIGAM) and by the Korea National Oil Corporation (KNOC), and Basic Science Research Program through the National Research Foundation of Korea (NRF) funded by the Ministry of Education (2021R1I1A1A01052612).

\section{References}

Aki, K., 1968, Seismic displacements near a fault. Journal of Geophysical Research, v. 73, pp. 5359-5376. doi:10.1029/JB073i016p05359

Bahorich, M., and Farmer, S., 1995, 3-D seismic discontinuity for faults and stratigraphic features: The coherence cube. The Leading Edge, v. 14, pp. 1053-1058. doi:10.1190/1.1437077

Bellahsen, N., and Daniel, J. M., 2005, Fault reactivation control on normal fault growth: an experimental study. Journal of Structural Geology, v. 27, pp. 769-780. doi:10.1016/j.jsg.2004.12.003

Brown, A. R., 2011, Interpretation of three-dimensional seismic data, seventh edition. AAPG Memoir 42, Society of Exploration Geophysicists and American Association of Petroleum Geologists, 315 p.

Chopra, S., and Marfurt, K. J., 2005, Seismic attributes-A historical perspective. Geophysics, v. 70, pp. 3SO-28SO. doi:10.1190/1.2098670

Chopra, S., and Marfurt, K. J., 2007, Seismic attributes for fault/fracture characterization. Proceedings SEG Technical Program Expanded Abstracts 2007, Society of Exploration Geophysicists, pp. 1520-1524. doi:10.1190/ 1.2792785

Chopra, S., Misra, S., and Marfurt, K. J., 2011, Coherence and curvature attributes on preconditioned seismic data. The Leading Edge, v. 30, pp. 386-393. doi:10.1190/1.3575281

Cohen, I., Coult, N., and Vassiliou, A. A., 2006, Detection and extraction of fault surfaces in 3D seismic data. Geophysics, v. 71, pp. 21-27. doi:10.1190/1.2215357

Cukur, D., Horozal, S., Kim, D. C., and Han, H. C., 2011, Seismic stratigraphy and structural analysis of the northern East China Sea Shelf 
Basin interpreted from multi-channel seismic reflection data and crosssection restoration. Marine and Petroleum Geology, v. 28, pp. 10031022. doi:10.1016/j.marpetgeo.2011.01.002

Dalley, R. M., Gevers, E. C. A., Stampfli, G. M., Davies, D. J., Gastaldi, C. N., Ruijtenberg, P. A., and Vermeer, G. J. O., 2007, Dip and azimuth displays for 3D seismic interpretation. First Break, v. 25. doi:10.3997/ 1365-2397.2007031

Dawers, N.H., and Anders, M.H., 1995, Displacement-length scaling and fault linkage. Journal of Structural Geology, v. 17, pp. 607-614. doi:10.1016/0191-8141(94)00091-D

Fossen, H., 2016, Structural geology. Cambridge, Cambridge University Press, $480 \mathrm{p}$.

Froner, B., Purves, S. J., Lowell, J., and Henderson, J., 2013, Perception of visual information: The role of colour in seismic interpretation. First Break, v. 31, pp. 29-34. doi:10.3997/1365-2397.2013010

Gersztenkorn, A., and Marfurt, K. J., 1999, Eigenstructure-based coherence computations as an aid to 3-D structural and stratigraphic mapping. Geophysics, v. 64, pp. 1468-1479. doi:10.1190/1.1444651

Guo, H., Lewis, S., and Marfurt, K. J., 2008, Mapping multiple attributes to three-and four-component color models - A tutorial. Geophysics, v. 73, pp. W7-W19. doi:10.1190/1.2903819

Hale, D., 2013, Methods to compute fault images, extract fault surfaces, and estimate fault throws from 3D seismic images. Geophysics, v. 78, pp. 33-43. doi:10.1190/geo2012-0331.1

Harris, C., and Stephens, M., 1988, A combined corner and edge detector. Proceedings of the 4th Alvey Vision Conference 1988, pp. 147-151. doi: $10.5244 / \mathrm{c} .2 .23$

Henderson, J., Purves, S. J., Fisher, G., and Leppard, C., 2008, Delineation of geological elements from RGB color blending of seismic attribute volumes. The Leading Edge, v. 27, pp. 342-350. doi:10.1190/1.2896625

Henning, A., and Paton, G., 2011, Understanding thin beds using 3D seismic analysis workflows. Proceedings 31st Annual Gulf Coast Section SEPM Foundation, Bob F. Perkins Research Conference, pp. 322-341. doi:10.5724/gcs.11.31.0322

Henza, A. A., Withjack, M. O., and Schlische, R. W., 2011, How do the properties of a pre-existing normal-fault population influence fault development during a subsequent phase of extension? Journal of Structural Geology, v. 33, pp. 1312-1324. doi:10.1016/j.jsg.2011.06.010

Iacopini, D., and Butler, R. W., 2011, Imaging deformation in submarine thrust belts using seismic attributes. Earth and Planetary Science Letters, v. 302, pp. 414-422. doi:10.1016/j.eps1.2010.12.041

Jibrin, B. W., Reston, T. J., and Westbrook, G. K., 2013, Application of volumetric seismic discontinuity attribute for fault detection: Case study using deep-water Niger Delta 3D seismic data. The Leading Edge, v. 32, pp. 424-428. doi:10.1190/tle32040424.1

Kwon, Y. I., and Boggs Jr., S., 2002, Provenance interpretation of Tertiary sandstones from the Cheju Basin (NE East China Sea): A comparison of conventional petrographic and scanning cathodoluminescence techniques. Sedimentary Geology, v. 152, pp. 29-43. doi:10.1016/S00370738(01)00284-6

Kwon, Y. I., Park, K. S., Yu, K. M., and Son, J. D., 1995, Stratigraphy and provenance of Non-marine sediments in the Tertiary Cheju Basin. Korean Journal of Petroleum Geology, v. 3, pp. 1-15 (in Korean with English abstract).

Langhi, L., Zhang, Y., Gartrell, A., Underschultz, J., and Dewhurst, D., 2010, Evaluating hydrocarbon trap integrity during fault reactivation using geomechanical three-dimensional modeling: An example from the Timor Sea, Australia. American Association of Petroleum Geologists Bulletin, v. 94, pp. 567-591. doi:10.1306/10130909046

Lee, C., Shinn, Y. J., Han, H. C., and Ryu, I. C., 2018, Structural evolution of two-stage rifting in the northern East China Sea Shelf Basin. Geological Journal, v. 54, pp. 2229-2240. doi:10.1002/gj.3292

Lee, G. H., Kim, B., Shin, K. S., and Sunwoo, D., 2006, Geologic evolution and aspects of the petroleum geology of the northern East China Sea shelf basin. AAPG bulletin, v. 90, pp. 237-260. doi:10.1306/

\section{0}

Liang, J., and Wang, H., 2019, Cenozoic tectonic evolution of the East China Sea Shelf Basin and its coupling relationships with the Pacific Plate subduction. Journal of Asian Earth Sciences, v. 171, pp. 376-387.

Li, D.Y., Guo, T.Y., Jiang, X.D., Zhao, H.Q., and Wang, H.P., 2015, Erosion thickness recovery and tectonic evolution characterization of southern East China Sea Shelf Basin. Oil Gas Geol, v. 36, pp. 913-923.

Mansfield, C. S., and Cartwright, J. A., 1996, High resolution fault displacement mapping from three-dimensional seismic data: evidence for dip linkage during fault growth. Journal of Structural Geology, v. 18, pp. 249-263. doi:10.1016/S0191-8141(96)80048-4

Marfurt, K. J., Kirlin, R. L., Farmer, S. H., and Bahorich, M. S., 1998, 3D seismic attributes using a running window semblance-based algorithm. Geophysics, v. 63, pp. 1150-1165. doi:10.1190/1.1444415

McArdle, N. J., Iacopini, D., KunleDare, M. A., and Paton, G. S., 2014, The use of geologic expression workflows for basin scale reconnaissance: A case study from the Exmouth Subbasin, North Carnarvon Basin, northwestern Australia. Interpretation, v. 2, pp. 163-177. doi:10.1190/ INT-2013-0112.1

Peacock, D. C. P., and Sanderson, D. J., 1991, Displacements, segment linkage and relay ramps in normal fault zones. Journal of Structural Geology, vol. 13, pp. 721-733. doi:10.1016/0191-8141(91)90033-F

Pigott, J. D., Kang, M. H., and Han, H. C., 2013, First order seismic attributes for clastic seismic facies interpretation: Examples from the East China Sea. Journal of Asian Earth Sciences, v. 66, pp. 34-54. doi:10.1016/ j.jseaes.2012.11.043

Reeve, M. T., Bell, R. E., Duffy, O. B., Jackson, C. A. L., and Sansom, E., 2015, The growth of non-colinear normal fault systems; What can we learn from 3D seismic reflection data?. Journal of Structural Geology, v. 70, pp. 141-155. doi:10.1016/j.jsg.2014.11.007

Shang, L. N., Zhang, X. H., Jia, Y. G., Han, B., Yang, C. S., Geng, W., and Pang, Y. M., 2017, Late Cenozoic evolution of the East China continental margin: Insights from seismic, gravity, and magnetic analyses. Tectonophysics, v. 698, pp. 1-15. doi:10.1016/j.tecto.2017.01.003

Taner, M. T., 2001, Seismic attributes. CSEG recorder, v. 26, pp. 49-56.

Taner, M. T., Schuelke, J. S., O'Doherty, R., and Baysal, E., 1994, Seismic attributes revisited. Proceedings SEG Technical Program Expanded Abstracts 1994, Society of Exploration Geophysicists, pp. 1104-1106. doi:10.1190/1.1822709

Wang, R., Shi, W., Xie, X., Tang, D., Manger, W., Busbey, A. B., and Xu, L., 2018, Boundary fault linkage and its effect on Upper Jurassic to Lower Cretaceous sedimentation in the Gudian half-graben, Songliao Basin, northeastern China. Marine and Petroleum Geology, v. 98, pp. 33-49. doi:10.1016/j.marpetgeo.2018.08.007

Yang, Q. L., 1992. Geotectonic framework of the East China Sea. In: J. S. Watkins, F. Zhiqiang, and K. J. McMillen (Eds.), Geology and geophysics of continental margins, AAPG Memoir 53, pp. 17-25. doi:10.1306/ M53552C2

Yang, S., Hu, S., Cai, D., Feng, X., Chen, L., and Gao, L., 2004, Presentday heat flow, thermal history and tectonic subsidence of the East China Sea Basin. Marine and Petroleum Geology, v. 21, pp. 1095-1105. doi:10.1016/j.marpetgeo.2004.05.007

Ye, J., Qing, H., Bend, S. L., and Gu, H., 2007, Petroleum systems in the offshore Xihu Basin on the continental shelf of the East China Sea. AAPG bulletin, v. 91, pp.1167-1188. doi:10.1306/02220705158

Yun, H., Yi, S., Kim, J. H., Byun, H. S., Kim, G. H., and Park, D. B., 1999, Biostratigraphy and paleoenvironment of the Cheju sedimentary basinbased on materials from explorations, Geobuk-1 and Okdom-1. Journal of the Paleontological Society of Korea, v. 15, pp. 43-94 (in Korean with English abstract).

Zhang, G., Li, S., Suo, Y., and Zhang, J., 2016, Cenozoic positive inversion tectonics and its migration in the East China Sea Shelf Basin. Geological Journal, v. 51, pp. 176-187.

Zhou, Z., Zhao, J., and Yin, P., 1989, Characteristics and tectonic evolution of the East China Sea. Chinese sedimentary basins, pp. 165-179. 


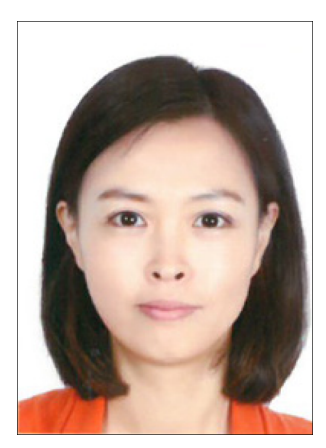

Juhwan Woo is post-doctoral researcher in Chungbuk National University, Korea. She received Ph.D. degree from Department of Earth and Environmental Sciences, Chungbuk National University, in 2018. She studied shale reservoir characterization. Her major interests are in sedimentology of shale as well as the reservoir characterization of integrate the diverse geophysical data such as core, well log, and seismic data.

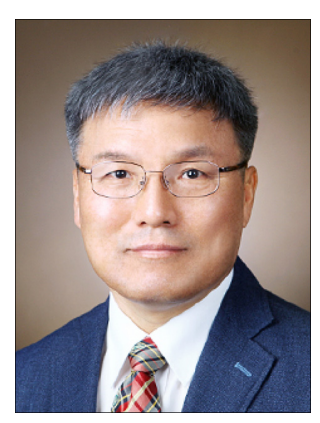

Chul Woo Rhee is a Professor of sedimentology in Chungbuk National University, Korea. He received his Ph.D. degree from School of Earth and Environmental Sciences, Seoul National University, Korea in 1995. His research interests range from field-based fluvial sedimentology, shale sedimentology, sequence stratigraphy to sedimentological interpretation of geophysical data such as well $\log$ data and seismic profiles.

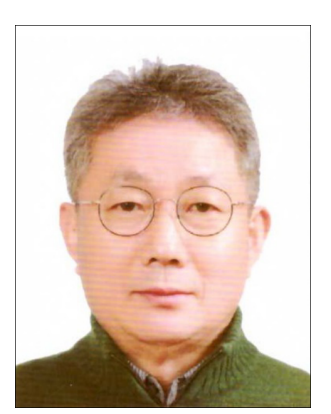

Ji Soo Kim is a Full Professor of Geophysics in Chungbuk National University, Korea. $\mathrm{He}$ received his Ph.D. degree from Department of Geological Sciences, University of Manitoba, Canada in 1993. He was awarded the 2015 Excellence in Science and Technology from the Korea KOFST. His research interests include land seismic data processing, electrical resistivity tomography, and multiple applied geophysics.

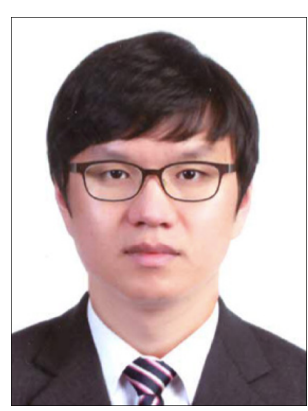

Bo-Sung Lim is Geophysicist(Manager) in Domestic Business Unit, Korea National Oil Corporation. He received his master's degree from Department of Energy Resource Engineering, Seoul National University, Korea in 2008. He has been dealing with seismic attributes, AVO (Amplitude versus Offset) analysis, seismic inversion and machine learning in reservoir characterization since he joined the company in 2008 . 